\title{
Estudo da viabilidade do preparo direto para descanso de cíngulo em incisivo central superior
}

\section{Study of the viability of the direct preparation of lingual rest seats in maxillary central incisors}

\author{
José Freire de ALENCAR* \\ Artêmio Luiz ZANETTI** \\ Moacyr D. NOVELLI*** \\ Bruno COSTA****
}

\begin{abstract}
ALENCAR, J. F.; ZANETTI, A. L.; NOVELLI, M. D.; COSTA, B. Estudo da viabilidade do preparo direto para descanso de cíngulo em incisivo central superior. Pesq Odont Bras, v. 14, n. 1, p. 71-78, jan./mar. 2000.
\end{abstract}

\begin{abstract}
Esta pesquisa teve como finalidade estudar a viabilidade do preparo direto para descanso em cíngulo de incisivo central superior, por intermédio de processamento de imagem. Foram reproduzidos dez dentes íntegros, montados em um suporte de alumínio com resina acrílica e distribuídos entre cinco especialistas, que executaram os preparos para descanso. Em seguida, os corpos-de-prova foram cortados ao longo de suas coroas, tendo como guia um corte inicial, feito no centro da borda incisal de cada dente. O preparo foi então dimensionado, estabelecendo-se medidas lineares e angulares que permitissem uma análise comparativa entre o perfil original do dente e aquele após o preparo, enquanto se determinava a perfuração ou não da camada de esmalte. Todas as observações foram feitas, digitalizando-se os perfis e processando as imagens num programa específico. Dos cinqüenta modelos preparados, seguindo critérios estabelecidos, trinta e três perfuraram a camada de esmalte. Sendo assim, o incisivo central superior não está indicado para receber preparo direto para descanso de cíngulo.
\end{abstract}

UNITERMOS: Prótese parcial removivel; Descanso; Resinas compostas; Processamento de imagens assistida por computador.

\section{INTRODUÇÃO}

O êxito da prótese parcial removivel depende da observância de alguns princípios básicos consagrados. Dentre estes, o que primeiro demanda a atenção no planejamento é o da fixação dada pelos apoios que, pela sua localização estratégica, transmitem as forças de modo eqüitativo aos suportes e impedem a intrusão cervical da prótese.

A primeira referência quanto a necessidade do apoio data de 1817, quando DELABARRE ${ }^{5}$ (1941) relatou uma irritação ao redor dos dentes suporte onde os grampos traumatizavam a margem gengival. O autor, apropriadamente, sugeriu a confecção de uma pequena extensão metálica para impedir a intrusão do aparelho. Posteriormente, BONWILL $^{2}$ (1899) apresentou uma técnica de confecção de grampos onde o apoio era soldado à estrutura do retentor e sugeriu que, nos dentes anteriores, se realizasse também um pequeno entalhe na região palatina para alojá-lo. De fato, o apoio deve sempre assentar-se sobre uma superficie com morfologia própria, o descanso, como preconizou $\mathrm{ROACH}^{15}$ já em 1930.

Nos dentes anteriores, este descanso deve ser preparado na face lingual, região do cíngulo, com formato aconcavado e profundidade suficiente para garantir a positividade e direcionamento das cargas mastigatórias para o longo eixo dos dentes suportes $^{12,19,20,22,23,24}$. A tentativa de se aproveitar a face lingual nos suportes anteriores sem o devido preparo inevitavelmente redunda no seu comprometimento, iatrogenia há muito reconhecida ${ }^{18}$.

Se por um lado a localização do descanso no cíngulo representa indiscutivel vantagem biomecânica e estética ${ }^{6,11,21}$, a área poucas vezes apresenta morfologia anatômica adequada para o seu preparo direto conforme textos clássicos ${ }^{1,9,11.13,22}$. Sem esta forma conveniente, o recurso seria uma restauração protética, o que acarretaria maior custo e

\footnotetext{
* Professor Assistente do Departamento de Dentística da Faculdade de Odontologia da Universidade do Estado do Rio de Janeiro.

** Professor Titular; ****Professor Doutor - Departamento de Prótese da Faculdade de Odontologia da Universidade de São Paulo.

*** Professor Doutor do Departamento de Estomatologia da Faculdade de Odontologia da Universidade de São Paulo.
} 
ALENCAR, J. F.; ZANETTI, A. L.; NOVELLI, M. D.; COSTA, B. Estudo da viabilidade do preparo direto para descanso de cíngulo em incisivo central superior. Pesq Odont Bras, v. 14, n. 1, p. 71-78, jan./mar. 2000.

menor aplicabilidade em nosso meio $\left(\mathrm{COSTA}^{3}\right.$ et al., 1991).

LIKEMAN; JUSZCZYK ${ }^{8}$ (1993) avaliaram dentes com apoios de cíngulo onde o descanso foi preparado sobre esmalte e compararam com outros onde o apoio ficou sem descanso. Concluíram que este descanso não poderia ter profundidade inferior a $0,5 \mathrm{~mm}$ para que sua forma fosse condicente com a distribuição axial de tensões. Vale lembrar que a espessura do esmalte na região correspondente ao cíngulo varia de 0,46 à $0,74 \mathrm{~mm}$, com uma média de $0,67 \mathrm{~mm}^{10,17}$.

A propósito, $\mathrm{JONES}^{7}$ et al. (1992) estudaram in vitro a exposição dentinária em caninos quando do preparo para descanso de cíngulo. Nos superiores, $55 \%$ apresentaram exposição, embora sejam estes os dentes de melhor prognóstico para receber estes preparos. Já nos inferiores, o percentual de exposição foi de $78 \%$, certamente devido ao menor volume desses dentes.

É curioso que, embora a dificuldade do preparo lingual direto constitua um consenso quase absoluto, estudos que corroborem esta hipótese são esparsos. Em se tratando dos incisivos como elemento de suporte, dados específicos não foram encontrados. Isso é também surpreendente, já que a longevidade destes dentes anteriores é notória, havendo inúmeros casos onde somente estes permaneceram como suportes da prótese reabilitadora. Esta lacuna objetivou o presente estudo.

\section{MATERIAL E MÉTODOS}

A possibilidade de se executar um descanso lingual somente sobre esmalte, sem que este preparo alcance a dentina, depende fundamentalmente da morfologia do dente e do trabalho técnico do profissional. Em função disso, o modelo experimental desenvolvido empregou dentes do mesmo biótipo, incisivos centrais superiores, que foram reproduzidos e distribuídos entre alguns dentistas para que preparassem um descanso lingual.

Objetivamente, o experimento pretendia uma comparação direta do perfil sagital do dente depois de preparado com o seu contorno original, sobrepondo-se imagens digitalizadas das duas situações por um processo gráfico em computador. O objetivo foi avaliar a extensão do desgaste quando da confecção do descanso. A metodologia levou em consideração somente a situação sagital, na altura da mediatriz mesiodistal do elemento, entendendo-se ser este ponto o mais crítico e portanto de maior interesse.

Dez incisivos centrais, superiores, permanentes e com coroas íntegras foram limpos de todo resto de tecido para serem incluídos em resina acrílica quimicamente ativada (Clássico Ltda., São Paulo) dentro de um perfil de alumínio (Incomental, São Paulo) com forma de "U" que funcionou como suporte do corpo-de-prova na sua fixação efetiva e preciso reposicionamento posterior na máquina de corte. A seguir, o corpo-de-prova foi adaptado na máquina de corte (Labcut 1010, Excel Technology Inc., USA), para que um pequeno entalhe de referência fosse executado na metade da extensão da borda incisal.

Cada dente montado foi então reproduzido com silicone (Profor Prod. e Form. Química - RTV - 573P - Plastitécnica Ltda. S. Paulo.) industrial e, seguindo-se as instruções do fabricante, depois de doze horas, o espécimen foi desmoldado, foi adaptado o perfil de alumínio no molde e vazado com gesso tipo IV (Velmix, Sybron Kerr Indústria e Comércio Ltda., São Paulo).

Um conjunto de dez diferentes modelos, referente a reprodução dos dentes, foi numerado e distribuído à cada um dos cinco profissionais selecionados. Foi solicitado que eles executassem, nestes modelos, preparos para descansos de cíngulo típicos, conforme critérios aceitos na Disciplina de Prótese Removivel da Faculdade de Odontologia da Universidade de São Paulo.

Após a realização dos preparos e valendo-se do posicionamento determinado pelo perfil metálico, os dentes originais e suas réplicas foram montados individualmente na máquina própria (Labcut 1010, Excel Technology Inc., USA) e cortados longitudinalmente, usando-se como guia o entalhe no meio da borda incisal e expondo o perfil para subseqüente utilização (Figura 1).

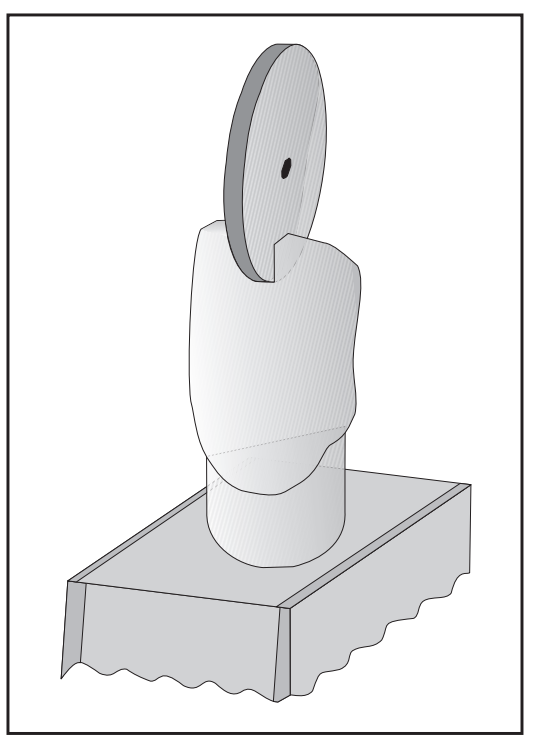

FIGURA 1 Ilustração do corpo-de-prova mostrando o dente incluído dentro da resina acrílica e dentro do perfil de alumínio em forma de "U". O disco na região incisal indica o sentido do corte executado para a análise do perfil. 
ALENCAR, J. F.; ZANETTI, A. L.; NOVELLI, M. D.; COSTA, B. Estudo da viabilidade do preparo direto para descanso de cíngulo em incisivo central superior. Pesq Odont Bras, v. 14, n. 1, p. 71-78, jan./mar. 2000.

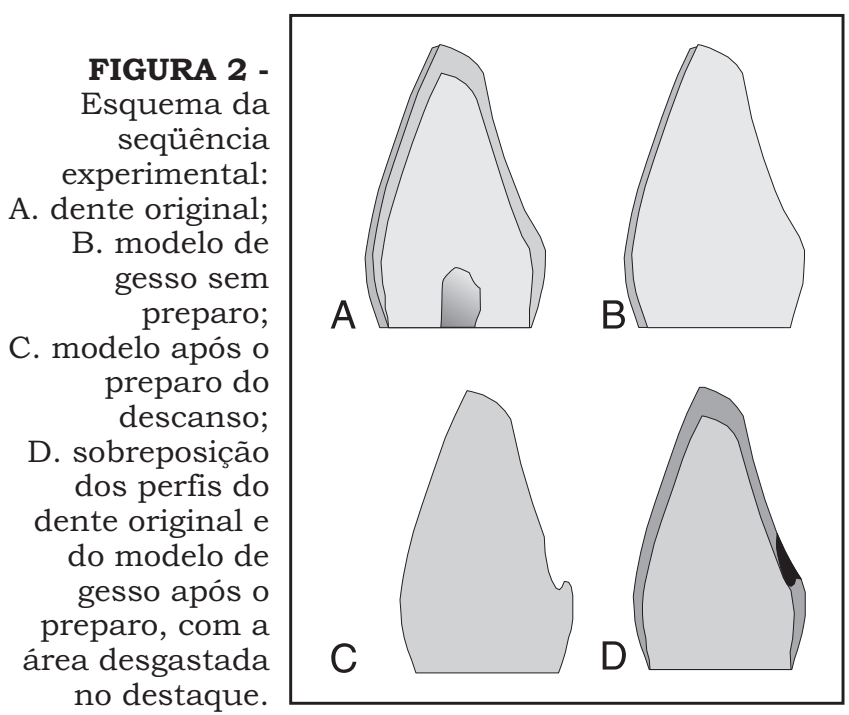

Para a obtenção das imagens para análise pelo aparelho de captação (FOTOVIX, Tamaron Corporation Ltda.), o dente original com um fundo escuro e uma de suas réplicas, sobre um fundo claro, foram alinhados entre si no monitor (TRINITON SONY, Japan). Recebendo iluminação intensa com uma fibra óptica (FIBRALUX, Dabi-Atlante, Ribeirão Preto) e utilizando-se recursos de editoração gráfica próprios do LIDO (Laboratório de Informática Dedicado à Odontologia), foram delimitadas áreas na região de cíngulo com ou sem preparo e digitalizadas ("congeladas") na posição conveniente. Modificando-se a transparência de uma das imagens (50\%), foi possivel sobrepô-las de modo a efetuar-se uma análise comparativa da geometria entre a condição antes e depois do preparo (Figura 2).

Para caracterizar a morfologia do descanso, os contornos encontrados foram definidos em termos de medidas angulares e lineares. Para tanto, nas imagens dos modelos preparados foram marcados pontos e linhas de referência tangenciando o preparo. Desta forma, delimitou-se: o ângulo alfa $(\alpha)$ formado pelas tangente do assoalho do preparo e sua parede axial e o ângulo beta ( $\beta$ ) formado pelo assoalho do preparo e o que seria o longo eixo do dente. Mediu-se também a distância entre o ponto mais incisal do desgaste axial e o limite cervical máximo do descanso designado de extensão axial. Os dados puderam ser complementados com os valores para a área total do desgaste e o fator de forma (Figura 3).

Com o intuito de se quantificar sua espessura, na imagem do corte conseguida com uma câmara

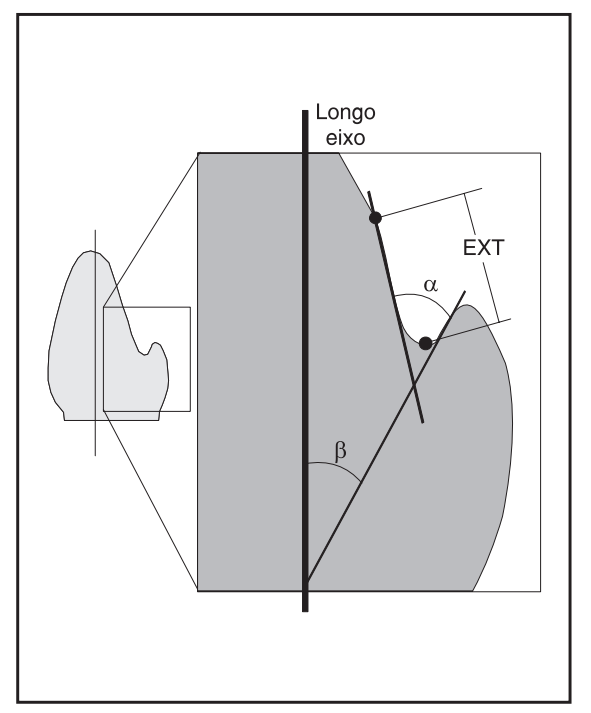

FIGURA 3 Ilustração da caracterização geométrica do preparo do descanso de cíngulo por intermédio de ângulos $(\alpha$ e $\beta)$ e medidas lineares (ext - extensão).

RGB (JVC, Japan) acoplada a um microscópio (Leitz Wetzlar, Portugal) foram realizadas medidas da camada de esmalte na concavidade palatina dos incisivos, adjacente a maior proeminência do cíngulo.

Outro aspecto importante foi determinar se o preparo do descanso levou à perfuração na camada de esmalte. Para esta mensuração, o dente original e o modelo em questão foram posicionados de modo que suas faces linguais ficassem voltadas uma para a outra, com as peças dispostas em direções contrárias e as regiões dos cíngulos alinhadas entre si. Verificou-se então, se a extensão do preparo levaria a perfuração ou, quando esta não pode ser constatada, mediu-se diretamente a espessura do esmalte remanescente.

\section{RESULTADOS}

A partir dos descansos realizados sobre os corpos-de-prova foram feitas medidas angulares e lineares para se correlacionar a sua morfologia e a perfuração da camada de esmalte (Tabela 1).

Dos cinqüenta corpos-de-prova examinados, trinta e três (66\%) preparos atingiram dentina. Dentre os que se mostraram aquém do limite amelo-dentinário, o remanescente de esmalte foi, em média, de 0,22 mm [0,07]* .

A média geral do ângulo $\beta$ para todos os preparos foi de $78,88^{\circ}$ [12] sendo que, para nenhum operador, ela superou $90^{\circ}$. Este dado condiz com o conceito que o assoalho do preparo deve descrever um ângulo agudo em relação ao longo eixo do dente suporte para garantir sua positividade. Cabe

\footnotetext{
* O desvio padrão ficará sempre entre [ ] quando não for designado por extenso.
} 
ALENCAR, J. F.; ZANETTI, A. L.; NOVELLI, M. D.; COSTA, B. Estudo da viabilidade do preparo direto para descanso de cíngulo em incisivo central superior. Pesq Odont Bras, v. 14, n. 1, p. 71-78, jan./mar. 2000.

TABELA 1 - Resultados das medidas angulares e lineares para a caracterização da morfologia do descanso preparado. Incluem-se os dados referentes à espessura do esmalte. (OP: designa o operador; Beta e Alfa: ângulos em graus; Área: medida de abrangência do preparo em $\mathrm{mm}^{2}$; Extns: extensão axial do preparo em mm.) Destacados os espécimens onde houve perfuração.

\begin{tabular}{|c|c|c|c|c|c|c|c|c|c|c|c|}
\hline \multicolumn{4}{|c|}{ OP1 } & \multicolumn{4}{|c|}{ OP2 } & \multicolumn{4}{|c|}{ OP3 } \\
\hline Beta & Alfa & Área & Extns & Beta & Alfa & Área & Extns & Beta & Alfa & Área & Extns \\
\hline 86,75 & 88,60 & 0,34 & 1,33 & 55,62 & 42,17 & 0,85 & 1,45 & 90,69 & 82,14 & 0,35 & 1,17 \\
\hline 75,47 & 84,80 & 0,54 & 1,57 & 59,02 & 78,39 & 0,72 & 1,76 & 56,38 & 61,28 & 0,19 & 1,20 \\
\hline 86,96 & 91,71 & 0,45 & 1,36 & 75,81 & 80,50 & 0,99 & 1,33 & 88,06 & 85,26 & 0,29 & 0,85 \\
\hline 76,05 & 91,66 & 0,45 & 1,15 & 60,29 & 65,42 & 0,58 & 1,30 & 91,26 & 120,40 & 0,27 & 1,04 \\
\hline 70,66 & 74,69 & 0,45 & 0,86 & 65,77 & 74,86 & 1,29 & 1,84 & 90,00 & 92,36 & 0,93 & 1,15 \\
\hline 85,24 & 96,88 & 0,45 & 1,49 & 59,07 & 66,52 & 1,85 & 3,24 & 65,84 & 87,17 & 0,56 & 1,06 \\
\hline 77,50 & 81,50 & 0,45 & 1,62 & 72,26 & 65,32 & 1,45 & 1,54 & 65,74 & 64,70 & 0,35 & 1,45 \\
\hline 74,51 & 80,97 & 0,45 & 1,81 & 45,07 & 59,45 & 1,99 & 2,90 & 77,67 & 95,58 & 0,42 & 0,72 \\
\hline 86,82 & 106,74 & 0,45 & 1,18 & 58,07 & 70,02 & 1,71 & 1,76 & 86,30 & 86,30 & 0,84 & 1,33 \\
\hline 89,47 & 92,99 & 0,45 & 1,84 & 80,88 & 83,60 & 2,08 & 4,97 & 79,79 & 88,72 & 0,53 & 1,28 \\
\hline \multicolumn{4}{|c|}{ OP4 } & \multicolumn{4}{|c|}{ OP5 } & \multirow{2}{*}{\multicolumn{4}{|c|}{ Espessura do Esmalte }} \\
\hline Beta & Alfa & Área & Extns & Beta & Alfa & Área & Extns & & & & \\
\hline 55,96 & 53,72 & 0,55 & 1,54 & 78,13 & 78,24 & 0,45 & 1,84 & \multicolumn{2}{|c|}{ Dente 01} & \multicolumn{2}{|c|}{0,78} \\
\hline 90,96 & 100,51 & 0,13 & 0,85 & 74,57 & 85,15 & 0,39 & 0,95 & \multicolumn{2}{|c|}{ Dente 02} & \multicolumn{2}{|c|}{0,82} \\
\hline 90,00 & 90,00 & 0,76 & 1,49 & 86,17 & 85,51 & 0,51 & 1,04 & \multicolumn{2}{|c|}{ Dente 03} & \multicolumn{2}{|c|}{0,85} \\
\hline 91,58 & 91,55 & 0,30 & 0,56 & 88,73 & 100,04 & 0,15 & 1,04 & \multicolumn{2}{|c|}{ Dente 04} & \multicolumn{2}{|c|}{0,81} \\
\hline 93,87 & 97,43 & 1,41 & 1,62 & 96,71 & 100,30 & 1,43 & 1,65 & \multicolumn{2}{|c|}{ Dente 05} & \multicolumn{2}{|c|}{0,75} \\
\hline 86,72 & 95,90 & 0,55 & 1,19 & 92,05 & 108,80 & 1,42 & 3,09 & \multicolumn{2}{|c|}{ Dente 06} & \multicolumn{2}{|c|}{0,66} \\
\hline 85,02 & 97,82 & 0,69 & 0,87 & 88,73 & 88,73 & 1,10 & 1,36 & \multicolumn{2}{|c|}{ Dente 07} & \multicolumn{2}{|c|}{0,75} \\
\hline 92,05 & 113,10 & 0,19 & 0,85 & 69,21 & 76,51 & 0,85 & 1,54 & \multicolumn{2}{|c|}{ Dente 08} & \multicolumn{2}{|c|}{0,72} \\
\hline 67,70 & 83,28 & 0,58 & 1,05 & 83,31 & 99,49 & 0,36 & 1,18 & \multicolumn{2}{|c|}{ Dente 09} & \multicolumn{2}{|c|}{0,80} \\
\hline 131,11 & 130,96 & 0,96 & 1,58 & 68,43 & 69,69 & 1,68 & 2,73 & \multicolumn{2}{|c|}{ Dente 10} & \multicolumn{2}{|c|}{0,78} \\
\hline
\end{tabular}

ressaltar que, somente em nove de todos os corpos-de-prova (18\%), este ângulo se apresentou maior que $90^{\circ}$ e destes, cinco $(52 \%)$ foram do mesmo profissional (OP4).

A média do ângulo $\beta$ para os dentes perfurados foi de $74,54^{\circ}\left[12,92^{\circ}\right]$; entre os não perfurados foi de $87,31^{\circ}\left[14,68^{\circ}\right]$. Verificamos que os dentes não perfurados tiveram valores significantemente maiores (1\%) em relação aos perfurados.

$\mathrm{O}$ ângulo $\alpha$ reflete a divergência das paredes axial e cervical do preparo. Dos cinqüenta ângulos medidos, dezenove (38\%) ultrapassaram o valor de $90^{\circ}$. O OP4 foi o que teve maior quantidade de ângulos acima deste valor (sete; 36\%) e o maior ângulo individual $\left(130,96^{\circ}\right)$. Cabe salientar que, à exceção do OP2, todos os demais tiveram pelo menos três ângulos superiores à $90^{\circ}$.

A média dos ângulos $\alpha$ para os dentes perfurados foi de $82,04^{\circ}\left[15,11^{\circ}\right]$; para os dentes não perfurados foi de $92,95^{\circ}\left[17,48^{\circ}\right]$. Esses valores demonstram diferenças com alta significância (1\%), ou seja, os dentes não perfurados tiveram ângulo $\alpha$ maiores que os perfurados.

Embora os dados referentes à extensão axial do 
ALENCAR, J. F.; ZANETTI, A. L.; NOVELLI, M. D.; COSTA, B. Estudo da viabilidade do preparo direto para descanso de cíngulo em incisivo central superior. Pesq Odont Bras, v. 14, n. 1, p. 71-78, jan./mar. 2000.

TABELA 2 - Análise de variância com determinação do valor crítico de Tukey. Comparação das médias (teste t) dos preparos com e sem perfuração. (OP: designa o operador; Beta e Alfa: ângulos em graus; Área: medida de abrangência do preparo em $\mathrm{mm}^{2}$; Extensão: extensão axial do preparo em mm; Forma: o fator de forma.)

\begin{tabular}{l|c|c|c|c|c}
\hline \hline & Beta & Alfa & Extensão & Área & Forma \\
\hline QM/Operador $^{\mathrm{a}}$ & 892,496 & 1017,527 & 2,0768 & 1,184 & 0,0070 \\
\hline QM-Resíduo $^{\mathrm{b}}$ & 156,740 & 209,440 & 0,4749 & 0,168 & 0,0131 \\
\hline RQM & 5,694 & 4,85 & 4,37 & 7,048 & 0,53 \\
\hline OP1.Médio $^{\text {OP2.Médio }}{ }^{\mathrm{c}}$ & 80,94 & 89,05 & 1,25 & 0,61 & 0,49 \\
\hline OP3.Médio & 63,19 & 68,62 & 2,20 & 1,35 & 0,50 \\
\hline OP4.Médio & 79,17 & 86,39 & 1,12 & 0,48 & 0,53 \\
\hline OP5.Médio & 88,50 & 95,43 & 1,17 & 0,61 & 0,53 \\
\hline Tukey & 82,50 & 89,25 & 1,64 & 0,83 & 0,47 \\
\hline Significância & 15,99 & 18,48 & 0,88 & 0,52 & - \\
\hline MED.PERF & $5 \%$ & $5 \%$ & $5 \%$ & $5 \%$ & NS \\
\hline Med.N/PERF & 84,54 & 82,041 & 1,75 & 0,91 & - \\
\hline Teste.T & 3,1596 & 92,945 & 1,04 & 0,50 & - \\
\hline Significância & $1 \%$ & 2,2909 & 3,5429 & 2,9689 & - \\
\hline \hline
\end{tabular}

(a) grau de liberdade: 4; (b) grau de liberdade: 45; (c) média significativamente diferente dos demais operadores.

preparo indique certa dispersão, $50 \%$ situam-se entre $1,00 \mathrm{~mm}$ a $1,55 \mathrm{~mm}$ e $90 \%$ dos preparos têm menos de $1,85 \mathrm{~mm}$ de extensão axial.

Analisando a diferença entre as médias dos operadores, observamos que o OP2 teve a maior média $(2,20 \mathrm{~mm})$ e que o OP3 teve a menor $(1,12$ $\mathrm{mm})$, sendo que OP2 perfurou todos os dentes por ele preparado, enquanto que o OP3 foi o que perfurou menos (quatro dentes). Esses dados apontam para uma correlação direta entre a extensão axial do preparo com a perfuração da dentina.

A medida da área desgastada também mostra alguns números bastante divergentes. Contudo, cerca de 49\% dos dentes estão entre 0,50 $1,00 \mathrm{~mm}^{2}$ e $90 \%$ tiveram preparos inferiores à 1,45 $\mathrm{mm}^{2}$.

A média das áreas para os dentes perfurados foi de $0,91 \mathrm{~mm}^{2}[0,53]$ e para os dentes não perfurados foi de $0,50 \mathrm{~mm}^{2}[0,27]$, o que representa uma diferença altamente significante $(1 \%)$.

$\mathrm{O}$ fator de forma é um índice que quantifica a relação entre a área* e o perímetro para indicar a variação da morfologia, independente do tamanho.
Por exemplo, círculos de diferentes tamanhos terão sempre fator de forma igual a 1, enquanto que superficies extremamente irregulares de áreas semelhantes tendem a zero. Pela análise, concluímos que os operadores executaram preparos estatisticamente iguais entre si, quanto à forma.

A espessura da camada de esmalte nos dez dentes foi medida por intermédio do microscópio óptico de luz e seus resultados estão relacionados (Tabela 1).

Genericamente, a análise de variância permite afirmar que existem diferenças significantes (5\%) entre as médias dos operadores quer quando considerados os ângulos quer quanto as medidas lineares (Tabela 2). No entanto, os dados para OP01, OP03, OP04 e OP05 são estatisticamente semelhantes. Por outro lado, ficou evidente que o OPO2 teve um comportamento significativamente diferente dos demais. Há de se ressaltar, contudo, que nos dentes perfurados quando do preparo do descanso, a caracterização do preparo indica que houve um procedimento significativamente diferente dos casos onde não fora constada a exposição den-

${ }^{*}$ Fator $=4 \pi$ Área $/$ Perímetro ${ }^{2}$. 
ALENCAR, J. F.; ZANETTI, A. L.; NOVELLI, M. D.; COSTA, B. Estudo da viabilidade do preparo direto para descanso de cíngulo em incisivo central superior. Pesq Odont Bras, v. 14, n. 1, p. 71-78, jan./mar. 2000.

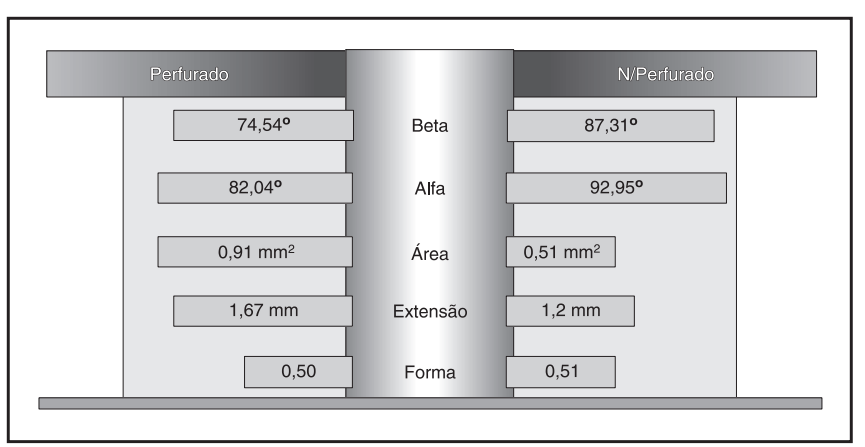

GRÁFICO 1 - Comparação entre as médias de diversas medidas lineares e angulares dos dentes com e sem perfuração do esmalte quando do preparo do descanso do cíngulo. Todos os valores apresentam diferença estatística significativa (1\%).

tinária, exceção feita à forma do preparo que foi rigorosamente igual em ambos os casos.

\section{DISCUSSÃO}

Somente em nove dos cinqüenta preparos verificou-se um valor acima de $90^{\circ}$ para o ângulo $\beta$. Este dado é importante porque demostra que em quase todos os descansos a parede gengival perfaz um ângulo agudo em relação ao longo eixo do dente, o que é considerado como ideal para este tipo de preparo, pela maioria dos textos clássicos ${ }^{9,20,22,25}$. Outros admitem que este ângulo pode ser reto ou agudo $^{4,13,14,23}$.

A média do ângulo $\beta$ dos dentes não perfurados foi significativamente $(1 \%)$ maior que a dos perfurados. Isto vale dizer que quanto mais agudo for o ângulo $\beta$, maior será a tendência de exposição da dentina no preparo do descanso (Gráfico 1).

Por outro lado, os valores para o ângulo $\alpha$ tendem a ser maiores que os para $\beta$; dezenove (38\%) dos cinqüenta valores medidos ficaram acima de $90^{\circ}$. Também aqui, nos dentes aonde houve perfuração, o ângulo foi significativamente $(1 \%)$ maior do que naqueles não perfurados.

Comparando os resultados parece coerente acreditar que quanto maiores os ângulos $\alpha$ e $\beta$, menores as chances de perfurar a camada de esmalte. Não encontramos nenhuma referência ao ângulo $\alpha$ em toda literatura pesquisada.

A literatura revista mostrou-se vaga quanto a questão da profundidade do descanso. Segundo alguns autores, a profundidade decorre da necessidade de se prover uma espessura suficiente para que o apoio resista mecanicamente enquanto sua morfologia possa garantir uma fixação efi-

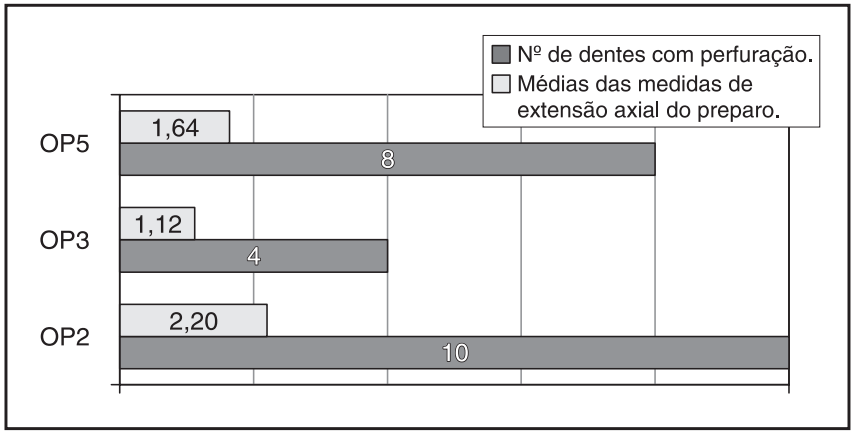

GRÁFICO 2 - Médias das medidas de extensão axial do preparo de três operadores (OP2, OP3, OP5) e o respectivo número de espécimens onde se verificou a perfuração da camada de esmalte.

ciente $^{22,25}$. No entanto, não indicam valores específicos. Outros autores recomendam desgaste entre 1 à $1,5 \mathrm{~mm}^{9,14,24}$.

No presente trabalho, a questão profundidade do preparo foi considerada sob três aspectos: extensão axial do preparo, área de preparo e fator de forma. Como todos os preparos se apresentaram estatisticamente equivalentes quanto a forma, este item não teve relevância nos resultados.

Quanto a extensão, podemos afirmar que existem diferenças significantes $(5 \%)$ entre as médias dos operadores. É bastante sugestivo o fato que OP5, que possui uma das maiores médias $(1,64 \mathrm{~mm})$ praticamente perfuraria todos os dentes com seus preparos. Por sua vez, OP3, com a menor média $(1,12 \mathrm{~mm})$, atingiria dentina apenas em quatro dos dez descansos. Estes dados sugerem que existe uma correlação direta entre a extensão axial do preparo e a perfuração da camada de esmalte (Gráfico 2) O OP2, com a maior extensão média $(2,20 \mathrm{~mm})$, atingiria dentina com todos os seus preparos.

Cabe salientar que, os dentes onde houve perfuração tiveram maior média de extensão axial do que os não perfurados; resultados altamente significativos (1\%). Os resultados sugerem que, quando os dentes recebem um preparo adequado para o descanso, é estatisticamente provável que haja perfuração da camada de esmalte, expondo a dentina.

JONES $^{7}$ et al. (1992) mostraram, in vitro, que haveria exposição dentinária quando do preparo de descansos no cíngulo de caninos superiores e inferiores. Isto foi confirmado por MENGAR (1996) em sua dissertação sobre preparos em caninos su- 
ALENCAR, J. F.; ZANETTI, A. L.; NOVELLI, M. D.; COSTA, B. Estudo da viabilidade do preparo direto para descanso de cíngulo em incisivo central superior. Pesq Odont Bras, v. 14, n. 1, p. 71-78, jan./mar. 2000.

periores, fato que o levou a considerar o descanso direto de alto risco para as estruturas dentárias.

Estes estudos foram corroborados pelos nossos resultados. De certa maneira, seria esperado que houvesse uma maior porcentagem de perfuração nos incisivos centrais superiores, que recebessem preparos diretos, visto que esses dentes são menos volumosos e sequer possuem cíngulo relativamente aos caninos.

Segundo MILLER; GRASSO ${ }^{11}$ (1990) e MCGIVNEY; CASTLEBERRY ${ }^{9}$ (1994), os incisivos centrais superiores não têm espessura suficiente de esmalte na região de cíngulo para receber o preparo direto do descanso. Nossos dados estão em comum acordo com esta premissa, pois, dos cinqüenta corpos-de-prova preparados houve perfuração em trinta e três (66\%), quando comparados com os respectivos dentes originais.

Nos dezessete onde a perfuração não ficou caracterizada, a espessura do esmalte remanescente foi extremamente delgada, levando a se supor que em local adjacente provavelmente houvera perfuração. Também há de se considerar nestes casos, a variabilidade na operacionalização do preparo uma vez que os ângulos assinalados foram bastante divergentes e a área de desgaste foi significante (1\%) menor quando comparados com os perfurados (Tabela 1). Esta variabilidade não necessariamente indique algum erro; especialmente se lem- brarmos que o fator de forma (Tabela 1) demonstra que todos os operadores realizaram preparos estatisticamente iguais quanto à sua forma.

Outro quesito importante é a espessura inicial da camada de esmalte (Tabela 1): o dente com a menor valor (D6) foi perfurado por todos os operadores enquanto que o dente com a maior espessura (D3) foi perfurado apenas por dois (OP2 e OP3). A espessura da camada de esmalte na região palatina da amostra foi em média de 0,77 $\mathrm{mm}$.

\section{CONCLUSÕES}

Todos os preparos executados apresentaram forma condizente e equivalente, independente do operador. A esmagadora maioria (66\%) da amostra apresentou perfuração da camada de esmalte quando do preparo dos descansos de cíngulo. Muito embora um único fator não possa ser singularizado como preponderante para este resultado, a caracterização morfológica dos descansos indica que, na medida em que o profissional atende aos preceitos básicos quanto a extensão e positividade, a possibilidade de se alcançar dentina aumenta significativamente. Por conseguinte, o preparo direto de descansos no incisivo central superior é desaconselhável face à probabilidade de comprometimento biológico.

ALENCAR, J. F.; ZANETTI, A. L.; NOVELLI, M. D.; COSTA, B. Study of the viability of the direct preparation of lingual rest seats in maxillary central incisors. Pesq Odont Bras, v. 14, n. 1, p. 71-78, jan./mar. 2000.

The present research evaluated the viability of the direct preparation of lingual rest seats in maxillary central incisors. Ten completely sound specimens were embedded in acrylic resin supports and distributed among five specialists who prepared the rest seats. The coronary portion of the teeth was then cut using a previously made incisal index as guide. The preparation was characterized by angular and linear measurements that enabled a comparative analysis between the original outline of the tooth and its respective prepared model, while permitting the determination of dentinal exposure. The observations were undertaken in digitized images of these outlines utilizing a specific computer program. From the fifty models prepared under well-established criteria, thirty-three showed perforation of the enamel. Conclusively, the maxillary central incisor may not be indicated to receive a directly prepared lingual rest seat.

UNITERMS: Denture, partial, removable; Rest seat; Composite resins; Image processing, computer assisted.

\section{REFERÊNCIAS BIBLIOGRÁFICAS}

1. APPLEGATE, O. C. Essentials of removable partial denture prosthesis. 3. ed. Philadelphia : Saunder. 1965. $436 \mathrm{p}$.

2. BONWILL, W. G. A. New methods of clasping artificial dentures to human teeth whithout injury versus immovable bridges. Dent Itens Interest, v. 21, p. 656-670, 1899.

3. COSTA, B.; GALVAN, R.; NAVARRO, H.; MUENCH, A.; TODESCAN, R. Apoios em cíngulo em resina composta para prótese parcial removivel - Aspectos de sua viabilidade clínica. Rev Assoc Paul Cir Dent, v. 45, n. 3, p. 450-459, maio/jun. 1991.

4. DE FIORI, S. R. Atlas de prótese parcial removivel. 3. ed. São Paulo : Pancast, 1989. 464 p.

5. DELABARRE, C. F. Discours d'ouverture d'un cours de médicine dentaire, 1817 , p. 14000 apud GIRARDOT, R. L. History and development of partial denture design. $\mathbf{J}$

Am Dent Assoc, v. 28, n. 9, p. 243-253, Sept. 1941.

6. JANUS, C. E.; SCHUFELDT, H. A.; BECK, D. A.; 
ALENCAR, J. F.; ZANETTI, A. L.; NOVELLI, M. D.; COSTA, B. Estudo da viabilidade do preparo direto para descanso de cíngulo em incisivo central superior. Pesq Odont Bras, v. 14, n. 1, p. 71-78, jan./mar. 2000.

McCASLAND, J. P.; ESHLEMAN, J. R. The use of custom cast-metal resin-bonded cingulum rest seats under removable partial dentures. Compendium Contin Educ Dent, v. 6, n. 5, p. 364-369, May 1985.

7. JONES, R. M.; GOODACRE, C. J.; BROWN, D. T.; MUNOZ, C. A.; RAKE, P.C. Dentin exposure and decay incidence when removable partial denture rest seats are prepared in tooth structure. Int $\mathbf{J}$ Prosthod, v. 5, n. 3, p. 227-236, May 1992.

8. LIKEMAN, P. R.; JUSZCZYK, A. S. An examination of cingulum rest seats in incisor and canine teeth. Eur $\mathbf{J}$ Prosthodont Restor Dent, v. 1, n. 4, p. 165-171, 1993.

9. McGiVney, G. P.; CASTLEBERRY, D. J. Prótese parcial removivel e McCRAKEN. Trad. Por Bruno Costa. 8. ed. São Paulo : Artes Médicas, 1994. 330 p.

10. MENGAR, M. A. Investigação sobre a espessura do esmalte remanescente após preparações de descansos de cíngulo realizados em caninos superiores, por intermédio do microscópio óptico de luz. São Paulo, 1996. 86 p. Dissertação (Mestrado em Prótese Dental) - Faculdade de Odontologia, Universidade de São Paulo.

11. MILLER, E. L.; GRASSO, J. E. Prótese parcial removivel. 2. ed. São Paulo: Santos, 1990. 432 p.

12. MILLS, E. L.; CREEK, B. Mouth preparation for the removable partial denture. J Am Dent Assoc, v. 60, n. 1, p. 154-159, Feb. 1960.

13. Osborne, J.; LAMMie, G. A. Partial dentures. 2. ed, Oxford : Blackwel Scientific Publications, 1959, 391 p.

14. RENNER, R. P.; BOUCHER, L. J. Removable partial dentures. Chicago: Quintessence, 1987. 415 p.

15. ROACH, F. E. Principles and essentials of bar clasp partial dentures. J Am Dent Assoc, v. 17, n. 1, p. 124-138, Jan. 1930.

16. RUDD, K. D.; DUNN, B. W. Accurate removable partial dentures. J Prosthet Dent, v. 18, n. 6, p. 559-561, Dec. 1967.

17. SHILLINGBURG JUNIOR, T. H.; GRACE, C. S. Thickness of enamel and dentin. South Calif Dent AssocJ, v.41, n. 1, p. 33-52, Jan.1973.

18. SCHUYLER, C. H. Planning the removable partial denture to restore function and mantain oral health. N Y State Dent J, v. 13, n. 1, p. 4-10, Jan. 1947.

19. SCHWARZ, W. D.; BARSBY, M. J. Tooth alteration procedures prior to partial denture construction. Part. 1. Dent Update, v. 11, n. 1, p. 19-34, Jan. 1984.

20. STEWART, K. L.; RUDD, K. D.; KUEBKER, W. A. Clinical removable partial prosthodontics. St Louis : Istriyaku Euro America, 1988. 715 p.

21. STRATTON, R. P.; WIEBELT, F. J. An atlas of removable partial denture design. Chicago : Quintessence Publishing Company, 1988, $335 \mathrm{p}$.

22. TODESCAN, R.; SILVA, E. E. B.; SILVA, O. J. Atlas de prótese parcial removivel. São Paulo : Santos. 1996. $345 \mathrm{p}$.

23. WEINBERG, L. A. Atlas of removable partial denture prosthodontics. Saint Louis : Mosby, 1969, 255 p.

24. WRIGHT, W. E. Abutment tooth modification for removable partial denture therapy. Compendium Contin Educ Dent, v. 10, n. 1, p. 40-46, 1989.

25. ZARB, G. A.; BERGMAN, B.; CLAYTON, J. A.; MacKAY, H. F. Prosthodontic treatment for partially edentulous patients. Saint Louis : Mosby, 1978. 619 p.

Recebido para publicação em 18/06/99 Enviado para reformulação em 08/10/99 Aceito para publicação em 20/12/99 